\title{
The carbon budget of a tundra in the north-eastern Russian Arctic during the snow free season and its stability in the 2003-2016 period
}

\author{
Han Dolman ${ }^{1}$, Jacobus van Huissteden ${ }^{1}$, Joshua Dean ${ }^{1,2}$, Trofim Maximov ${ }^{3,4}$, Roman Petrov ${ }^{3,4}$, and \\ Luca Belelli Marchesini ${ }^{5}$ \\ ${ }^{1}$ Department of Earth Sciences, Vrije Universiteit Amsterdam, Amsterdam, the Netherlands \\ ${ }^{2}$ School of Environmental Sciences, University of Liverpool, Liverpool, United Kingdom \\ ${ }^{3}$ Institute for Biological Problems of the Cryolithozone, Siberian Branch Russian Academy of Sciences, Yakutsk, Russia \\ ${ }^{4}$ North-Eastern Federal University, Yakutsk, Russia \\ ${ }^{5}$ Department of Sustainable Agro-ecosystems and Bioresources, Research and Innovation Centre, Fondazione Edmund \\ Mach, San Michele all'Adige, Italy
}

Large quantities of carbon are stored in the terrestrial permafrost of the Arctic region where the rate of climate warming is two to three times more than the global mean and the largest temperature anomalies observed in autumn and winter. The quantification of the impact of climate warming on the degradation of permafrost and the associated potential release to the atmosphere of carbon stocked in the soil in the form of greenhouse gases, thus further increasing the radiative forcing of the atmosphere, is a research priority in the field of biogeosciences. Landatmosphere turbulent fluxes of $\mathrm{CO}_{2}$ and $\mathrm{CH}_{4}$ have been monitored at the tundra site of Kytalyk in north-eastern Siberia (70,82 N; 147.48 E) by means of eddy covariance since 2003 and 2008, respectively; regular measurement campaigns have been carried out since then. Here we present results of the seasonal $\mathrm{CO}_{2}$ budget of the tundra ecosystem for the 2003-2016 period based on observations encompassing the permafrost thawing season and analyze the inter-annual differences in the seasonal patterns of $\mathrm{CO}_{2}$ fluxes considering the separate the contribution of climatic drivers and ecosystem functional parameters relative to the processes of respiration and photosynthesis. The variability of the $\mathrm{CO}_{2}$ budget is also discussed in view of the impact of the timing and length of the snow free period.

The Kytalyk tundra acted as an atmospheric carbon dioxide sink with relatively small inter-annual variability $\left(-96.1 \pm 11.9 \mathrm{gC} \mathrm{m}^{-2}\right)$ during the snow free season and the seasonal $\mathrm{CO}_{2}$ budget did not show any trend over time. The pronounced meteorological variability characterizing Arctic summers was a key factor in shaping the length of the carbon uptake period, which did not progressively increased despite its tendency to start earlier, and in determining the magnitude of $\mathrm{CO}_{2}$ fluxes. No clear evidence of inter-annual changes in the eco-physiological response parameters of $\mathrm{CO}_{2}$ fluxes to climatic drivers (global radiation and air temperature) was found along the course of the analysed period. Methane fluxes had a minor contribution to the carbon budget of the snow-free season representing on average an emission of $3.2 \mathrm{gC} \mathrm{m}^{-2}$ (2008-2016) with apparently small inter-annual variability. Similarly, the size of the carbon exported laterally from the ecosystem in the form of dissolved organic carbon flux amounted to $3.1 \mathrm{gC} \mathrm{m}^{-2}$ as 
determined experimentally. After including these last terms in the budget, the magnitude of the carbon sink associated with the net ecosystem productivity is reduced by $6 \%$, while the GHG budget still denotes a sink of $-60.4 \pm 11.9$ gC- $\mathrm{CO}_{2}$ eq (methane GWP over 100-year time horizon).

The monitored tundra was to date exerting a steady climate warming mitigation effect as far as the snow free season is concerned, however the figure of its carbon sink could be potentially sensibly lower due to overlooked emissions in the autumn freeze-up and early winter periods. Also, nonlinear accelerations in the permafrost degradation could happen once tipping points in the Arctic climate are exceeded. Both aspects underline the relevance of long term and continuous biogeochemical monitoring in permafrost tundra environments. 